\title{
The Journal of Cardiovascular Nursing
}

\section{A systematic review of interventions to improve the health factors and behaviors associated with the cardiovascular health of prisoners during incarceration --Manuscript Draft--}

\begin{tabular}{|l|l|}
\hline Manuscript Number: & JCN-D-16-00274R2 \\
\hline Full Title: & $\begin{array}{l}\text { A systematic review of interventions to improve the health factors and behaviors } \\
\text { associated with the cardiovascular health of prisoners during incarceration }\end{array}$ \\
\hline Article Type: & Review of Literature \\
\hline Keywords: & Prisoners; cardiovascular health; intervention studies \\
\hline Corresponding Author: & $\begin{array}{l}\text { Andrea RM Mohan, MPH } \\
\text { University of Stirling } \\
\text { Stirling, UNITED KINGDOM }\end{array}$ \\
\hline $\begin{array}{l}\text { Corresponding Author Secondary } \\
\text { Information: }\end{array}$ & \begin{tabular}{l} 
University of Stirling \\
\hline Corresponding Author's Institution:
\end{tabular} \\
\hline $\begin{array}{l}\text { Corresponding Author's Secondary } \\
\text { Institution: }\end{array}$ & Andrea RM Mohan, MPH \\
\hline First Author: & \\
\hline First Author Secondary Information: & Andrea RM Mohan, MPH \\
\hline Order of Authors: & Patricia Thomson, PhD \\
\hline Stephen J Leslie, PhD \\
\hline Elena Dimova, MSc. \\
\hline Order of Authors Secondary Information: & Sally Haw, BSc. \\
\hline Janet McKay, DNurs \\
\hline
\end{tabular}

Publisher policy allows this work to be made available in this repository. Mohan A, Thomson P, Leslie S, Dimova E, Haw S \& McKay JA (2018) A Systematic Review of Interventions to Improve Health Factors or Behaviors of the Cardiovascular Health of Prisoners During Incarceration. Journal of Cardiovascular Nursing, 33 (1), pp. 72-81. This paper is not the copy of record. The final published version is available at: https://doi.org/10.1097/jcn.0000000000000420. 


\section{Abstract}

Background: Prisoners are disproportionately affected by cardiovascular disease and its risk factors. However, primary prevention of cardiovascular disease in correctional settings has been widely neglected and there is little information on interventions to improve the cardiovascular health of prisoners while incarcerated. Objective: To systematically review published literature to identify interventions to improve the health factors or behaviors of the cardiovascular health of prisoners during incarceration.

Methods: Selected databases were searched using terms related to prisoners and cardiovascular disease. Studies were included if they had prisoners as participants and measured outcomes of cardiovascular health. Narrative synthesis was used to organize the evidence from the studies.

Results: Twelve papers detailing 11 studies were identified. Most of the studies involved only males. Interventions were classified into four types: structured physical activity; nutrition; mixed with physical activity and education sessions; and smoking cessation. Most studies measured short-term outcomes relating to cardiovascular health such as changes in blood pressure and weight. Only four studies were of high quality. Structured physical activity interventions, nutrition interventions and smoking cessation interventions delivered in a group setting had significant effects on at least one measured outcome. The effect of mixed interventions could not be determined. Conclusion: Structured physical activity interventions, nutrition interventions and smoking cessation interventions delivered in a group setting can improve health factors or behaviors of the cardiovascular health of prisoners during incarceration. More high-quality research is needed to increase the evidence base on the effectiveness of these interventions in the correctional setting. 


\section{Introduction}

Cardiovascular disease (CVD) is the leading cause of death worldwide and it accounted for approximately 17.5 million deaths in $2012 .{ }^{1}$ The most common modifiable risk factors of CVD, physical inactivity, unhealthy diet, tobacco use and excessive alcohol use, are also common risk factors of other non-communicable diseases (NCDs). ${ }^{2}$ These risk factors disproportionately affect certain groups such as women, ethnic minorities and prisoners. ${ }^{3}$

Prisoners tend to have poorer health than the general population ${ }^{4}$ and there is a higher prevalence of the common modifiable risk factors of CVD in this population compared to the general population. 5,6 This is due to the high percentage of prisoners being involved in high risk behaviors, for example, $64 \%$ to $92 \%$ of prisoners smoke. ${ }^{5}$ In some countries, this represents three times the prevalence of smoking in the general population. ${ }^{7}$ Incarceration can also significantly increase prisoners' risk of hypertension ${ }^{8}$ and CVD has shown to be a major cause of death in prisoners both in and out of prison. . $^{9-11}$

The correctional environment can be very stressful and as a result, many prisoners suffer from mental health issues such as anxiety and depression which have been associated with CVD. ${ }^{6}$ Thus those in positions of authority have a responsibility to provide environments which promote positive prisoner health and wellbeing. Prisoner health is of public health importance as most prisoners will eventually be released back into the community, carrying with them their existing health problems which can increase the burden on public health resources. ${ }^{12}$ 
CVD mortality and morbidity can be reduced by implementing interventions designed to target its modifiable risk factors. ${ }^{2}$ Several guidelines exist which provide evidencebased recommendations to reduce these factors. ${ }^{13-15}$ Behavior change interventions in particular have been recommended in reducing these risk factors. ${ }^{16}$ Interventions which involved physician advice, individual counseling, teaching behavioral skills and those that were tailored to the individual's needs have shown to be effective in targeting these risk factors. ${ }^{17,18}$ Unfortunately such interventions have been more geared towards the public domain from which prisons are usually excluded.

Although CVD and its risk factors are major health problems for prisoners, primary prevention and treatment for NCDs including CVD has largely been neglected. ${ }^{5}$ This is possibly due to a perception that, because the majority of prisoners are young, CVD may not be an issue. ${ }^{12}$ There is a need to challenge such perceptions and to implement interventions to promote the cardiovascular health for prisoners. Encouraging prisoners to change their health behaviors while incarcerated could potentially improve their cardiovascular and general health during incarceration, ${ }^{19,20}$ and help improve the health of those who are eventually released into the community.

One recent systematic review identified 95 randomized controlled trials (RCTs) that evaluated interventions to improve the health of prisoners but only two of these focused specifically on cardiovascular health. ${ }^{21}$ The authors looked at RCTs ${ }^{21}$ but studies with this design can be difficult to conduct in a prison setting due to several factors including randomization, anonymity and blinding. This current systematic review was therefore conducted to identify interventions used to improve health 
factors or behaviors of the cardiovascular health of prisoners during incarceration and to assess their effectiveness.

\section{Methods}

Search strategy and inclusion criteria

The search strategy followed PRISMA guidelines ${ }^{22}$ to identify all relevant articles. An electronic search for articles was performed in CINAHL, MEDLINE via OVID, PubMed, PsychINFO and the Knowledge Network from inception to May 2016. The following terms were used in individual searches: 'prisoners', 'offenders', 'exercise', 'training', nutrition', 'diet', 'smoking cessation', 'cardiovascular', 'health promotion', and 'wellness'. Each individual search was then combined to identify articles. An example of a search using CINHAL is given in Table 1.

The inclusion criteria for this review were peer-reviewed studies that were based in a correctional setting and had participants who were current prisoners. In this review the term 'prisoners' refers to people incarcerated in prisons, jails and other correctional institutions, including inmates and offenders.

As the nature of correctional regimes makes it difficult to randomize prisoners, studies of differing designs (including RCTs) were included to not eliminate any potentially important studies. Studies had to observe outcomes of at least one of the following health factors and behaviors related to cardiovascular health as outlined by the American Heart Association ${ }^{23}$ : blood pressure; cholesterol levels; blood glucose levels; physical activity; diet; weight and smoking status. Studies were excluded if they only presented baseline results or if they measured outcomes after participants 
were released from prison as this review looked at the effect on prisoners while are incarcerated.

A full list of articles was obtained and then screened for duplicates. Abstracts were reviewed to identify the articles according to the inclusion criteria. Reference lists of relevant articles were searched by hand to identify any appropriate studies that could potentially be included in the review. The search strategy and selected full-text articles were reviewed and verified by another researcher (ED). Any discrepancies were discussed. The search strategy is summarized in Figure 1.

\section{Narrative synthesis}

Narrative synthesis was used to organize the evidence from the studies. This approach is used when studies are too methodologically diverse to be combined in a meta-analysis.. ${ }^{24}$ Data were extracted from the studies using a data extraction template designed for use in the review. The studies were then grouped according to the type of intervention they described, and were presented in tabular form. For all studies, data were extracted on study design, sample size, sample characteristics, type of intervention, intervention duration and outcomes of the study.

\section{Quality assessment}

The quality of the studies was assessed using the Quality Assessment Tool for Quantitative Studies developed by the Effective Public Health Practice Project (EPHPP). ${ }^{25} \mathrm{~A}$ detailed definition of the tool is provided to clarify the assessment process. ${ }^{26}$ The EPHPP tool was selected above other tools such as the Cochrane Collaboration Risk of Bias Tool (CCRBT) as it allows for the assessment of range of study designs, and therefore does not limit the number of studies that can be 
included in the review based on design. ${ }^{27}$ All articles were independently assessed by two researchers (AM and ED) and any discrepancies were discussed and resolved.

\section{Results}

In total, 833 articles were retrieved, and after removing duplicates, having screened abstracts and full-texts, 12 articles detailing 11 studies were included in this review. The results from one study were published in two papers. ${ }^{28,29}$ The studies were all carried out in high-income countries: four in the U.S.A., ${ }^{28-32}$ two in Australia, ${ }^{33,34}$ two in Spain, $, 35,36$ and one each in Italy, ${ }^{37}$ Belgium, ${ }^{38}$ and Canada. ${ }^{39}$ Eight studies included only males, ${ }^{30-34,36-38}$ two included only females $28,29,39$ and one included both males and females. ${ }^{35}$

\section{Structured physical activity interventions}

Four studies evaluated the effect of supervised structured physical activity interventions (Table 2). ${ }^{30,31,36,37}$ Changes in different clinical factors such as blood pressure and cholesterol levels, and changes in physical fitness factors such as muscular endurance and strength were measured. Two studies compared a single intervention group which participated in an exercise program to a control group. ${ }^{30,36}$ One study observed significant positive effects on the physical fitness of prisoners, ${ }^{30}$ while the other study did not observe any significant effects. ${ }^{36}$ Two studies compared two or more intervention groups to a control group. ${ }^{31,37}$ One study which evaluated two different training protocols found that cardiovascular and resistance training was more effective in improving the physical fitness of prisoners compared to high intensity strength training. ${ }^{37}$ The other study compared exercise frequency and found 
that more frequent exercise had more positive effects on body composition compared to less frequent exercise. ${ }^{31}$

\section{Nutrition interventions}

Three studies evaluated the effect of nutrition interventions (Table 3). ${ }^{32,35,38}$ Two studies measured health-related outcomes such as BMI, abdominal perimeter, blood pressure and cholesterol levels. ${ }^{35,38}$ Both studies evaluated interventions in which the diet of prisoners were modified. One changed the entire diet of prisoners according to their health needs, ${ }^{35}$ while the other supplied a diet enhanced with fatty acids. ${ }^{38}$ The study that changed entire diets observed significant positive effects on the body composition of intervention participants, ${ }^{35}$ while the other study which used enhanced fatty acid supplementation only observed significant positive effects on diastolic blood pressure and high density lipoproteins in prisoners who smoked. ${ }^{38}$ The third study evaluated the impact of education and behavioral workshops on the nutrition practices of prisoners. ${ }^{32}$ This study found that nutrition education and reinforcement of positive healthy nutrition habits had a significantly positive effect on prisoners' nutrition practices.

\section{Mixed interventions}

Two studies evaluated mixed interventions that combined physical activity and education sessions (Table 4). ${ }^{34,39}$ Both studies used a prisoner or prisoners to lead part or all of the intervention. One study evaluated the effect of supervised physical activity combined with health education classes on the health of prisoners with chronic illness or risk factors for a chronic illness. ${ }^{34}$ Changes in anthropometric and clinical variables were measured including weight, blood pressure and blood glucose 
levels. Significant positive effects were only observed for resting heart rate and endurance.

The other study evaluated the effect of a nutrition and fitness program on the health and wellbeing of female prisoners. ${ }^{39}$ The program incorporated the use of behavior change techniques such as self-monitoring of eating behavior and goal-setting to help prisoners track their personal fitness progress. ${ }^{39}$ Changes in weight, BMI, waistto-hip ratio and chest diameter were measured but only a significant positive effect was observed for chest diameter.

\section{Smoking cessation interventions}

Two studies evaluated the effect of smoking cessation interventions on smoking abstinence in prisoners (Table 5). ${ }^{28,29,33}$ Both studies used nicotine replacement therapy along with behavioral therapy to support smoking cessation. One study delivered the intervention in a group setting and focused on mood management training to prevent smoking relapse based on previous cognitive-behavioral research. ${ }^{28,29} \mathrm{~A}$ significant positive effect on smoking abstinence one week after the quit date was observed, and this significant effect was sustained up to six months post intervention.

The other study delivered two face-to-face brief cognitive-behavioral therapy (bCBT) sessions to prisoners and had support systems in place in the form of a telephone counseling service and self-help materials such as booklets and a quit calendar. ${ }^{33}$ This intervention had no significant effect on smoking abstinence. 


\section{Study quality}

The studies varied in terms of overall quality (Table 6). Three studies received a strong overall rating, ${ }^{35,36,38}$ four received a moderate overall rating ${ }^{28-30,33,37}$ and four received a weak overall rating. ${ }^{31,32,34,39}$ Most of the 'weak' studies had selection bias, did not report the withdrawal rates of participants or had high dropout rates of participants. Most studies received a strong rating for study design, considering confounders and using reliable data collection methods.

\section{Discussion}

This is the first systematic review of interventions to improve the health factors or behaviors of the cardiovascular health of prisoners during incarceration. Twelve studies evaluating 11 separate interventions were included. All the studies were conducted in high-income countries and most involved male prisoners. The interventions that were evaluated were classified into four types: structured physical activity, nutrition, mixed with physical activity and education sessions, and smoking cessation. Eight studies measured outcomes related to the health factors associated with cardiovascular health, ${ }^{30,31,34-39}$ while three studies measured outcomes related to behaviors associated with cardiovascular health. ${ }^{28,29,32}$ Most of these were shortterm outcomes. The majority of studies received a moderate or weak quality rating.

There is a clear gap in the literature regarding interventions to improve the health factors and behaviors of the cardiovascular health of prisoners while incarcerated, as evident by the small number of studies identified. This is an important finding considering the high prevalence of modifiable CVD risk factors in this population. ${ }^{6}$ 
The small number of smoking cessation studies in particular is worth noting, considering that smoking could be up to two or three times more prevalent in prisoners compared to the general population. ${ }^{40,41}$

\section{Effectiveness of interventions}

Given the small number of studies in this review, most of which were not of strong quality, there is limited evidence to support their overall effectiveness to improve the key health factors and behaviors of the cardiovascular health of prisoners. However, the positive results from some of the studies indicate that interventions involving supervised structured physical activity, diet modification, nutrition education and smoking cessation can improve the cardiovascular health of prisoners while incarcerated.

The four physical activity interventions involved structured exercises that were supervised but differed in terms of duration, frequency, intensity and type of exercise. Three out of the four interventions had significant effects on three or more health-related and physical fitness outcomes. ${ }^{30,31,37}$ This suggests that supervised structured physical activity only can be used as an intervention to improve the cardiovascular health of male prisoners while incarcerated.

Regarding the nutrition studies, two evaluated interventions in which prisoners adopted a passive role where their diets were modified without their input. ${ }^{35,38}$ Both these interventions had significant positive effects on at least two measured outcomes. There can be benefits to providing diet modification interventions to prisoners as many correctional institutions provide diets that are high in salt and calories. ${ }^{42}$ However, the effectiveness of these interventions can be reduced where 
prisoners have access to canteens which provide foods that are usually high in sugar and fat. ${ }^{43}$ Additionally, many prisoners tend to make unhealthy choices regarding their food intake, ${ }^{44}$ and therefore providing nutrition education and support to prisoners to help them make healthier dietary choices may be more feasible. The third nutrition intervention comprised of nutrition education workshops that allowed prisoners to adopt a more active role by taking part in a project and doing homework. ${ }^{32}$ There was a significant improvement in nutrition practices for prisoners who received this intervention. Improved nutrition practices could benefit prisoners given that they are provided with healthy food options.

The two studies that evaluated mixed interventions had a positive significant effect on at least one measured outcome..$^{34,39}$ However both studies had small sample sizes and were of weak quality, therefore their effectiveness could not be determined. Both studies usefully incorporated behavior change techniques (BCTs) which can encourage positive behavior change. ${ }^{45}$ However neither study mentioned the use of behavior change theory to guide the choice of BCTs used in their interventions, although one study did base its intervention on the self-identified health concerns of its participants. ${ }^{39,46}$

The two smoking cessation studies evaluated the effect of behavioral therapy combined with nicotine replacement on smoking abstinence in prisoners. ${ }^{28,29,33}$ Only one of the interventions had a positive significant effect on smoking abstinence in female prisoners. ${ }^{28,29} \mathrm{~A}$ possible reason for this is that these prisoners received a greater number of support sessions (10 sessions) $)^{28,29}$ compared to those in the other study (2 sessions). ${ }^{33}$ Another possibility is that the intervention involving female prisoners was delivered in a group setting; ${ }^{28,29}$ this strategy is considered to be more 
successful in improving long-term quit rates compared to self-help strategies. ${ }^{47}$ Although both studies did not give details to justify the use of BCTs, both did make reference to previous research based on the use of behavioral therapy to support smoking cessation.

\section{Implications for future research}

The majority of studies included in this review were of weak or moderate quality which brings into question the validity of their findings. They were still included in this review as details of their interventions could be useful in the development of future, more robust studies to improve the cardiovascular health of prisoners. Additionally, most of the studies involved male prisoners only but there is a need for more studies involving female prisoners, particularly as they are a prisoner sub-group that is disproportionately affected with CVD risk factors, especially lack of physical activity. 6,48

Although the two interventions in which prisoners adopted a more active role were of weak quality, ${ }^{32,39}$ there are benefits to incorporating this element in future interventions. By giving prisoners a more active role in interventions, for example, involving them in the intervention design, there can be promotion of selfempowerment, encouragement of communication and shared-decision making and other self-care skills which are traditionally difficult to foster in correctional settings. ${ }^{5}$

Most studies did not describe the process of implementing their interventions, which, given the complexities and influence of the prison environment, is important. Factors such as security and the inflexible nature of the prison regime can create major challenges for prison research. ${ }^{49}$ In our review, details of security levels were given 
in six studies (Tables 2-5). Overall though, there was little detail provided on the difficulties of intervention implementation relating to security. One study was unable to directly assess an outcome because prisoners were not allowed to leave the prison to access the equipment required to carry out this assessment. ${ }^{36}$ Another study attributed a lack of proper 'institutionalization' on its difficulty to fully integrate the intervention into the prison regime, but did not explain what this meant. ${ }^{35}$ Describing the implementation process of these interventions could benefit future researchers who are seeking to improve the cardiovascular health of prisoners.

\section{Conclusion}

In conclusion, this is the first systematic review examining the effectiveness of interventions to improve the key health factors and behaviors of the cardiovascular health of prisoners while incarcerated. Overall, the findings suggest that interventions involving supervised structured physical activity, diet modification, nutrition education and smoking cessation can improve some of these factors such as blood pressure, cholesterol levels and smoking status. However, more rigorous studies are needed to increase the evidence base as there was a lack of high quality studies. The majority of studies used male prisoners and assessed only the shortterm effectiveness of the interventions. Although some studies incorporated behavior change techniques, there was minimal reference made to behavior change theory to justify the use of these techniques within the interventions. There was also little information provided regarding the implementation process of interventions given the challenges of correctional environments. Therefore, future research should include female prisoners, assess short-term and long-term outcomes to evaluate intervention 
effectiveness, and support the use of behavior change techniques with evidencebased theory. Future studies should also provide more detail on the intervention implementation process within the correctional setting, as this information could help other researchers to understand and prepare for the challenges posed by the correctional setting.

\section{References}

1. Mendis S, Armstrong T, Bettcher D, et al. Global status report on noncommnicable diseases 2014. Geneva: World Health Organization; 2014.

2. WHO. Global action plan for the prevention and control of noncommunicable diseases 2013-2020. Geneva: World Health Organization; 2013.

3. Yeates K, Lohfeld L, Sleeth J, Morales F, Rajkotia Y, Ogedegbe O. A global perspective on cardiovascular disease in vulnerable populations. Can J Cardiol. 2015; 31(9): 1081-1093.

4. Fazel S, Baillargeon J. The health of prisoners. Lancet. 2011; 377: 956-965.

5. Plugge E, Martin RE, Hayton P. Noncommunicable diseases and prisoners. In: Enggist S, Møller L, Galea G, Udesen C, eds. Prisons and health. Marmorvej, Copenhagen: WHO Regional Office for Europe; 2014: 81-86.

6. Arries EJ, Maposa S. Cardiovascular risk factors among prisoners: An integrative review. J Forensic Nurs. 2013; 9(1): 52-64.

7. Ritter C, Stover H, Levy M, Etter JF, Elger B. Smoking in prisons: The need for effective and acceptable interventions. J Public Health Pol. 2011; 32(1): 32-45. 
8. Binswanger IA, Krueger PM, Steiner JF. Prevalence of chronic medical conditions among jail and prison inmates in the USA compared with the general population. $J$ Epidemiol Community Health. 2009; 63(11): 912-919.

9. Noonan M, Ginder S. Mortality in local jails and state prisons, 2000-2011, statistical tables. Washington, DC: US Department of Justice, Bureau of Justice Statistics; 2013.

10. Grant JR, Southall PE, Fowler DR, Mealey J, Thomas EJ, Kinlock TW. Death in custody: A historical analysis. J Forensic Sci. 2007; 52(5): 1177-1181.

11. Binswanger IA, Stern MF, Deyo RA, et al. Release from prison-a high risk of death for former inmates. N Engl J Med. 2007; 356(2): 157-165.

12. Enggist S, Møller L, Galea G, Udesen C, eds. Prisons and health. Copenhagen, Denmark: WHO Regional Office for Europe; 2014.

13. NICE. Evidence update 50 - prevention of cardiovascular disease. Manchester: National Institute for Health and Care Excellence. 2014.

14. JBS3. Joint British Societies' consensus recommendations for the prevention of cardiovascular disease (JBS3). Heart. 2014; 100: ii1-ii67.

15. Eckel RH, Jakicic JM, Ard JD, et al. 2013 AHA/ACC guideline on lifestyle management to reduce cardiovascular risk: A report of the American College of Cardiology/American Heart Association Task Force on practice guidelines. J Am Coll Cardiol. 2013.

16. Mendis S, Puska P, Norrving B, eds. Global atlas on cardiovascular disease prevention and control. Geneva: World Health Organization; 2011. 17. Jepson R, Harris F, Platt S, Tannahill C. The effectiveness of interventions to change six health behaviours: A review of reviews. BMC Public Health. 2010; 10(1): 1. 
18. Hillsdon M, Foster C, Cavill NC, H., Naidoo B. The effectiveness of public health interventions for increasing physical activity among adults: A review of reviews:

Evidence briefing summary. 2nd ed. London: Health Development Agency; 2005. 19. Kinner SA, Wang EA. The case for improving the health of ex-prisoners. Am J Public Health. 2014; 104(8): 1352-1355.

20. Restum ZG. Public health implications of substandard correctional health care. Am J Public Health. 2005; 95(10): 1689-1691.

21. Kouyoumdjian FG, Mclsaac KE, Liauw J, et al. A systematic review of randomized controlled trials of interventions to improve the health of persons during imprisonment and in the year after release. Am J Public Health. 2015; 105(4): e13e33.

22. Moher D, Liberati A, Tetzlaff J, Altman DG, The PRISMA Group. Preferred reporting items for systematic reviews and MetaAnalyses: The PRISMA statement. PLoS Med. 2009; 6(7):29. doi:e1000097.

23. Go AS, Mozaffarian D, Roger VL, et al. Heart disease and stroke statistics 2013 update: A report from the American Heart Association. Circulation. 2013;127: e6-e245.

24. Centre for Reviews and Dissemination. Systematic reviews: CRD's guidance for undertaking reviews in health care. York, UK: Centre for Reviews and Dissemination; 2009.

25. EPHPP. Quality assessment tool for quantitative studies. http://www.ephpp.ca/PDF/Quality\%20Assessment\%20Tool_2010_2.pdf. Published 1998. Accessed January 13, 2015. 
26. EPHPP. Quality assessment tool for quantitative studies dictionary.

http://www.ephpp.ca/PDF/QADictionary_dec2009.pdf. Published 1998. Accessed January 13, 2015.

27. Armijo-Olivo S, Stiles CR, Hagen NA, Biondo PD, Cummings GG. Assessment of study quality for systematic reviews: A comparison of the Cochrane Collaboration risk of bias tool and the Effective Public Health Practice Project quality assessment tool: Methodological research. J Eval Clin Pract. 2012; 18(1): 12-18.

28. Cropsey K, Jackson D, Hale G, Carpenter M, Stitzer M. Impact of self-initiated pre-quit smoking reduction on cessation rates: Results of a clinical trial of smoking cessation among female prisoners. Addict Behav. 2011; 36(1-2): 73-78.

29. Cropsey K, Eldridge G, Weaver M, Villalobos G, Stitzer M, Best A. Smoking cessation intervention for female prisoners: Addressing an urgent public health need. Am J Public Health. 2008; 98(10): 1894-1901.

30. Amtmann J, Evans R, Powers J. Measured and perceived effects of a correctional wellness program. Correct Compend. 2001; 26(9): 1-6.

31. Gettman LR, Pollock ML, Durstine JL, Ward A, Ayres J, Linnerud AC. Physiological responses of men to 1, 3, and 5 day per week training programs. Res Q Exercise Sport. 1976; 47(4): 638-646.

32. Curd P, Ohlmann K, Bush H. Effectiveness of a voluntary nutrition education workshop in a state prison. J Correct Health Care. 2013; 19(2): 144-150.

33. Richmond R, Indig D, Butler T, Wilhelm K, Archer V, Wodak A. A randomized controlled trial of a smoking cessation intervention conducted among prisoners. Addiction. 2012; 108(5): 966-974. 
34. Cashin A, Potter E, Stevens W, Davidson K, Muldoon D. Fit for prison: Special population health and fitness programme evaluation. Int J Prison Health. 2008; 4(4): 208-216.

35. Gil-Delgado Y, Domínguez-Zamorano JA, Martínez-Sánchez-Suárez E. Assessment of health benefits from a nutrition program aimed at inmates with cardiovascular risk factors at Huelva prison. Rev Esp Sanid Penit. 2011; 13: 75-83. 36. Pérez-Moreno F, Cámara-Sánchez M, Tremblay JF, Riera-Rubio VJ, Gil-Paisán L, Lucia A. Benefits of exercise training in Spanish prison inmates. Int J Sports Med. 2007; 28(12): 1046-1052.

37. Battaglia C, di Cagno A, Fiorilli G, et al. Benefits of selected physical exercise programs in detention: a randomized controlled study. Int $J$ Environ Res Public Health. 2013; 10(11): 5683-5696.

38. Sioen I, Hacquebard M, Hick G, et al. Effect of ALA-enriched food supply on cardiovascular risk factors in males. Lipids. 2009; 44(7): 603-611.

39. Elwood Martin R, Adamson S, Korchinski M, et al. Incarcerated women develop a nutrition and fitness program: Participatory research. Int J Prison Health. 2013; 9(3): 142-150.

40. Baybutt M, Ritter C, Stöver H. Tobacco use in prison settings: A need for policy implementation. In: Enggist S, Møller L, Galea G, Udesen C, eds. Prisons and health. Marmorvej, Copenhagen: WHO Regional Office for Europe; 2014: 138-147. 41. Djachenko A, St John W, Mitchell C. Smoking cessation in male prisoners: A literature review. Int J Prison Health. 2015; 11(1): 39-48.

42. Herbert K, Plugge E, Foster C, Doll H. Prevalence of risk factors for noncommunicable diseases in prison populations worldwide: A systematic review. Lancet. 2012; 379(9830): 1975-1982. 
43. Tammam J, Gillam L, Gesch B, Stein J. Availability of junk food should be reduced. BMJ. 2012; 345: e7070.

44. Condon L, Hek G, Harris F. Choosing health in prison: Prisoners' views on making healthy choices in English prisons. Health Educ J. 2008; 67(3): 155-166.

45. van Achterberg T, Huisman-de Waal GG, Ketelaar NA, Oostendorp RA, Jacobs JE, Wollersheim HC. How to promote healthy behaviours in patients? an overview of evidence for behaviour change techniques. Health Promot Int. 2011; 26(2): 148-162. 46. Elwood Martin R, Murphy K, Hanson D, et al. The development of participatory health research among incarcerated women in a Canadian prison. Int $J$ Prison Health. 2009; 5(2): 95-107.

47. Zwar NA, Mendelsohn CP, Richmond RL. Supporting smoking cessation. BMJ. 2014; 348: f7535.

48. Plugge EH, Foster CE, Yudkin PL, Douglas N. Cardiovascular disease risk factors and women prisoners in the UK: The impact of imprisonment. Health Promot Int. 2009; 24(4): 334-343.

49. Cislo AM, Trestman R. Challenges and solutions for conducting research in correctional settings: The U.S. experience. Int J Law Psychiatry. 2013; 36(3-4): 304310.

\section{Figure legend}

Figure 1 - Search strategy for the identification of articles 
Dear Editor,

RE: JCN-D-16-00274R1, entitled "A systematic review of interventions to improve the health factors and behaviors associated with the cardiovascular health of prisoners during incarceration"

Thank you for your response to our submitted paper, and we thank the reviewers for their comments. Please find below a response to the comments.

\section{Response to the reviewers' comments}

1) Comment: Please remove the bullets from your text and incorporate the bulleted list into the text. Thanks.

Response: The bullets points have been removed and incorporated into the text as recommended. 


\section{Title Page}

\section{A systematic review of interventions to improve health factors or behaviors of the cardiovascular health of prisoners during incarceration}

Andrea RM Mohan, MPH; Patricia Thomson, PhD; Stephen Leslie, PhD; Elena Dimova, MSc; Sally Haw, BSc; Janet McKay, DNurs.

Andrea RM Mohan, MPH. PhD researcher, Faculty of Health Sciences and Sport, University of Stirling.

Patricia Thomson, PhD, RN. Senior Lecturer, Faculty of Health Sciences and Sport, University of Stirling.

Stephen J Leslie, PhD, FRCP. Consultant Cardiologist, Raigmore Hospital, NHS Highland and Honorary Professor, Faculty of Health Sciences and Sport, University of Stirling.

Elena Dimova, MSc. PhD researcher, Faculty of Health Sciences and Sport, University of Stirling.

Sally Haw, BSc. Professor of Public and Population Health, Faculty of Health Sciences and Sport, University of Stirling.

Janet A McKay, DNurs, RN. Consultant Nurse, Cardiac Care, University Hospital Crosshouse, NHS Ayrshire and Arran.

Correspondence: Andrea Mohan, Faculty of Health Sciences and Sport, University of Stirling, Stirling, Scotland, FK9 4LA (a.r.mohan@stir.ac.uk; (+44) 1786 466116). 
Funding source: This manuscript is a result of an ongoing $\mathrm{PhD}$ study funded by the University of Stirling and NHS Ayrshire \& Arran, Scotland.

Conflicts: The authors have no conflicts of interest to disclose.

Number of words in the text: 2973 . Number of tables: 6 . Number of figures: 1 
Key words-Keywords must be compatible with MeSH headings

in Medline

\section{Keywords}

Prisoners; cardiovascular health; intervention studies 


\section{Abstract}

Background: Prisoners are disproportionately affected by cardiovascular disease and its risk factors. However, primary prevention of cardiovascular disease in correctional settings has been widely neglected and there is little information on interventions to improve the cardiovascular health of prisoners while incarcerated. Objective: To systematically review published literature to identify interventions to improve the health factors or behaviors of the cardiovascular health of prisoners during incarceration.

Methods: Selected databases were searched using terms related to prisoners and cardiovascular disease. Studies were included if they had prisoners as participants and measured outcomes of cardiovascular health. Narrative synthesis was used to organize the evidence from the studies.

Results: Twelve papers detailing 11 studies were identified. Most of the studies involved only males. Interventions were classified into four types: structured physical activity; nutrition; mixed with physical activity and education sessions; and smoking cessation. Most studies measured short-term outcomes relating to cardiovascular health such as changes in blood pressure and weight. Only four studies were of high quality. Structured physical activity interventions, nutrition interventions and smoking cessation interventions delivered in a group setting had significant effects on at least one measured outcome. The effect of mixed interventions could not be determined. Conclusion: Structured physical activity interventions, nutrition interventions and smoking cessation interventions delivered in a group setting can improve health factors or behaviors of the cardiovascular health of prisoners during incarceration. More high-quality research is needed to increase the evidence base on the effectiveness of these interventions in the correctional setting. 


\section{Introduction}

Cardiovascular disease (CVD) is the leading cause of death worldwide and it accounted for approximately 17.5 million deaths in $2012 .{ }^{1}$ The most common modifiable risk factors of CVD, physical inactivity, unhealthy diet, tobacco use and excessive alcohol use, are also common risk factors of other non-communicable diseases (NCDs). ${ }^{2}$ These risk factors disproportionately affect certain groups such as women, ethnic minorities and prisoners. ${ }^{3}$

Prisoners tend to have poorer health than the general population ${ }^{4}$ and there is a higher prevalence of the common modifiable risk factors of CVD in this population compared to the general population. 5,6 This is due to the high percentage of prisoners being involved in high risk behaviors, for example, $64 \%$ to $92 \%$ of prisoners smoke. ${ }^{5}$ In some countries, this represents three times the prevalence of smoking in the general population. ${ }^{7}$ Incarceration can also significantly increase prisoners' risk of hypertension ${ }^{8}$ and CVD has shown to be a major cause of death in prisoners both in and out of prison. . $^{9-11}$

The correctional environment can be very stressful and as a result, many prisoners suffer from mental health issues such as anxiety and depression which have been associated with CVD. ${ }^{6}$ Thus those in positions of authority have a responsibility to provide environments which promote positive prisoner health and wellbeing. Prisoner health is of public health importance as most prisoners will eventually be released back into the community, carrying with them their existing health problems which can increase the burden on public health resources. ${ }^{12}$ 
CVD mortality and morbidity can be reduced by implementing interventions designed to target its modifiable risk factors. ${ }^{2}$ Several guidelines exist which provide evidencebased recommendations to reduce these factors. ${ }^{13-15}$ Behavior change interventions in particular have been recommended in reducing these risk factors. ${ }^{16}$ Interventions which involved physician advice, individual counseling, teaching behavioral skills and those that were tailored to the individual's needs have shown to be effective in targeting these risk factors. ${ }^{17,18}$ Unfortunately such interventions have been more geared towards the public domain from which prisons are usually excluded.

Although CVD and its risk factors are major health problems for prisoners, primary prevention and treatment for NCDs including CVD has largely been neglected. ${ }^{5}$ This is possibly due to a perception that, because the majority of prisoners are young, CVD may not be an issue. ${ }^{12}$ There is a need to challenge such perceptions and to implement interventions to promote the cardiovascular health for prisoners. Encouraging prisoners to change their health behaviors while incarcerated could potentially improve their cardiovascular and general health during incarceration, ${ }^{19,20}$ and help improve the health of those who are eventually released into the community.

One recent systematic review identified 95 randomized controlled trials (RCTs) that evaluated interventions to improve the health of prisoners but only two of these focused specifically on cardiovascular health. ${ }^{21}$ The authors looked at RCTs ${ }^{21}$ but studies with this design can be difficult to conduct in a prison setting due to several factors including randomization, anonymity and blinding. This current systematic review was therefore conducted to identify interventions used to improve health 
factors or behaviors of the cardiovascular health of prisoners during incarceration and to assess their effectiveness.

\section{Methods}

Search strategy and inclusion criteria

The search strategy followed PRISMA guidelines ${ }^{22}$ to identify all relevant articles. An electronic search for articles was performed in CINAHL, MEDLINE via OVID, PubMed, PsychINFO and the Knowledge Network from inception to May 2016. The following terms were used in individual searches: 'prisoners', 'offenders', 'exercise', 'training', nutrition', 'diet', 'smoking cessation', 'cardiovascular', 'health promotion', and 'wellness'. Each individual search was then combined to identify articles. An example of a search using CINHAL is given in Table 1.

The inclusion criteria for this review were peer-reviewed studies that were based in a correctional setting and had participants who were current prisoners. In this review the term 'prisoners' refers to people incarcerated in prisons, jails and other correctional institutions, including inmates and offenders.

As the nature of correctional regimes makes it difficult to randomize prisoners, studies of differing designs (including RCTs) were included to not eliminate any potentially important studies. Studies had to observe outcomes of at least one of the following health factors and behaviors related to cardiovascular health as outlined by the American Heart Association ${ }^{23}$ : blood pressure; cholesterol levels; blood glucose levels; physical activity; diet; weight and smoking status. Studies were excluded if they only presented baseline results or if they measured outcomes after participants 
were released from prison as this review looked at the effect on prisoners while are incarcerated.

A full list of articles was obtained and then screened for duplicates. Abstracts were reviewed to identify the articles according to the inclusion criteria. Reference lists of relevant articles were searched by hand to identify any appropriate studies that could potentially be included in the review. The search strategy and selected full-text articles were reviewed and verified by another researcher (ED). Any discrepancies were discussed. The search strategy is summarized in Figure 1.

\section{Narrative synthesis}

Narrative synthesis was used to organize the evidence from the studies. This approach is used when studies are too methodologically diverse to be combined in a meta-analysis.. ${ }^{24}$ Data were extracted from the studies using a data extraction template designed for use in the review. The studies were then grouped according to the type of intervention they described, and were presented in tabular form. For all studies, data were extracted on study design, sample size, sample characteristics, type of intervention, intervention duration and outcomes of the study.

\section{Quality assessment}

The quality of the studies was assessed using the Quality Assessment Tool for Quantitative Studies developed by the Effective Public Health Practice Project (EPHPP). ${ }^{25} \mathrm{~A}$ detailed definition of the tool is provided to clarify the assessment process. ${ }^{26}$ The EPHPP tool was selected above other tools such as the Cochrane Collaboration Risk of Bias Tool (CCRBT) as it allows for the assessment of range of study designs, and therefore does not limit the number of studies that can be 
included in the review based on design. ${ }^{27}$ All articles were independently assessed by two researchers (AM and ED) and any discrepancies were discussed and resolved.

\section{Results}

In total, 833 articles were retrieved, and after removing duplicates, having screened abstracts and full-texts, 12 articles detailing 11 studies were included in this review. The results from one study were published in two papers. ${ }^{28,29}$ The studies were all carried out in high-income countries: four in the U.S.A., ${ }^{28-32}$ two in Australia, ${ }^{33,34}$ two in Spain, $, 35,36$ and one each in Italy, ${ }^{37}$ Belgium, ${ }^{38}$ and Canada. ${ }^{39}$ Eight studies included only males, ${ }^{30-34,36-38}$ two included only females $28,29,39$ and one included both males and females. ${ }^{35}$

\section{Structured physical activity interventions}

Four studies evaluated the effect of supervised structured physical activity interventions (Table 2). ${ }^{30,31,36,37}$ Changes in different clinical factors such as blood pressure and cholesterol levels, and changes in physical fitness factors such as muscular endurance and strength were measured. Two studies compared a single intervention group which participated in an exercise program to a control group. ${ }^{30,36}$ One study observed significant positive effects on the physical fitness of prisoners, ${ }^{30}$ while the other study did not observe any significant effects. ${ }^{36}$ Two studies compared two or more intervention groups to a control group. ${ }^{31,37}$ One study which evaluated two different training protocols found that cardiovascular and resistance training was more effective in improving the physical fitness of prisoners compared to high intensity strength training. ${ }^{37}$ The other study compared exercise frequency and found 
that more frequent exercise had more positive effects on body composition compared to less frequent exercise. ${ }^{31}$

\section{Nutrition interventions}

Three studies evaluated the effect of nutrition interventions (Table 3). ${ }^{32,35,38}$ Two studies measured health-related outcomes such as BMI, abdominal perimeter, blood pressure and cholesterol levels. ${ }^{35,38}$ Both studies evaluated interventions in which the diet of prisoners were modified. One changed the entire diet of prisoners according to their health needs, ${ }^{35}$ while the other supplied a diet enhanced with fatty acids. ${ }^{38}$ The study that changed entire diets observed significant positive effects on the body composition of intervention participants, ${ }^{35}$ while the other study which used enhanced fatty acid supplementation only observed significant positive effects on diastolic blood pressure and high density lipoproteins in prisoners who smoked. ${ }^{38}$ The third study evaluated the impact of education and behavioral workshops on the nutrition practices of prisoners. ${ }^{32}$ This study found that nutrition education and reinforcement of positive healthy nutrition habits had a significantly positive effect on prisoners' nutrition practices.

\section{Mixed interventions}

Two studies evaluated mixed interventions that combined physical activity and education sessions (Table 4). ${ }^{34,39}$ Both studies used a prisoner or prisoners to lead part or all of the intervention. One study evaluated the effect of supervised physical activity combined with health education classes on the health of prisoners with chronic illness or risk factors for a chronic illness. ${ }^{34}$ Changes in anthropometric and clinical variables were measured including weight, blood pressure and blood glucose 
levels. Significant positive effects were only observed for resting heart rate and endurance.

The other study evaluated the effect of a nutrition and fitness program on the health and wellbeing of female prisoners. ${ }^{39}$ The program incorporated the use of behavior change techniques such as self-monitoring of eating behavior and goal-setting to help prisoners track their personal fitness progress. ${ }^{39}$ Changes in weight, BMI, waistto-hip ratio and chest diameter were measured but only a significant positive effect was observed for chest diameter.

\section{Smoking cessation interventions}

Two studies evaluated the effect of smoking cessation interventions on smoking abstinence in prisoners (Table 5). ${ }^{28,29,33}$ Both studies used nicotine replacement therapy along with behavioral therapy to support smoking cessation. One study delivered the intervention in a group setting and focused on mood management training to prevent smoking relapse based on previous cognitive-behavioral research. ${ }^{28,29} \mathrm{~A}$ significant positive effect on smoking abstinence one week after the quit date was observed, and this significant effect was sustained up to six months post intervention.

The other study delivered two face-to-face brief cognitive-behavioral therapy (bCBT) sessions to prisoners and had support systems in place in the form of a telephone counseling service and self-help materials such as booklets and a quit calendar. ${ }^{33}$ This intervention had no significant effect on smoking abstinence. 


\section{Study quality}

The studies varied in terms of overall quality (Table 6). Three studies received a strong overall rating, ${ }^{35,36,38}$ four received a moderate overall rating ${ }^{28-30,33,37}$ and four received a weak overall rating. ${ }^{31,32,34,39}$ Most of the 'weak' studies had selection bias, did not report the withdrawal rates of participants or had high dropout rates of participants. Most studies received a strong rating for study design, considering confounders and using reliable data collection methods.

\section{Discussion}

This is the first systematic review of interventions to improve the health factors or behaviors of the cardiovascular health of prisoners during incarceration. Twelve studies evaluating 11 separate interventions were included. All the studies were conducted in high-income countries and most involved male prisoners. The interventions that were evaluated were classified into four types: structured physical activity, nutrition, mixed with physical activity and education sessions, and smoking cessation. Eight studies measured outcomes related to the health factors associated with cardiovascular health, ${ }^{30,31,34-39}$ while three studies measured outcomes related to behaviors associated with cardiovascular health. ${ }^{28,29,32}$ Most of these were shortterm outcomes. The majority of studies received a moderate or weak quality rating.

There is a clear gap in the literature regarding interventions to improve the health factors and behaviors of the cardiovascular health of prisoners while incarcerated, as evident by the small number of studies identified. This is an important finding considering the high prevalence of modifiable CVD risk factors in this population. ${ }^{6}$ 
The small number of smoking cessation studies in particular is worth noting, considering that smoking could be up to two or three times more prevalent in prisoners compared to the general population. ${ }^{40,41}$

\section{Effectiveness of interventions}

Given the small number of studies in this review, most of which were not of strong quality, there is limited evidence to support their overall effectiveness to improve the key health factors and behaviors of the cardiovascular health of prisoners. However, the positive results from some of the studies indicate that interventions involving supervised structured physical activity, diet modification, nutrition education and smoking cessation can improve the cardiovascular health of prisoners while incarcerated.

The four physical activity interventions involved structured exercises that were supervised but differed in terms of duration, frequency, intensity and type of exercise. Three out of the four interventions had significant effects on three or more health-related and physical fitness outcomes. ${ }^{30,31,37}$ This suggests that supervised structured physical activity only can be used as an intervention to improve the cardiovascular health of male prisoners while incarcerated.

Regarding the nutrition studies, two evaluated interventions in which prisoners adopted a passive role where their diets were modified without their input. ${ }^{35,38}$ Both these interventions had significant positive effects on at least two measured outcomes. There can be benefits to providing diet modification interventions to prisoners as many correctional institutions provide diets that are high in salt and calories. ${ }^{42}$ However, the effectiveness of these interventions can be reduced where 
prisoners have access to canteens which provide foods that are usually high in sugar and fat. ${ }^{43}$ Additionally, many prisoners tend to make unhealthy choices regarding their food intake, ${ }^{44}$ and therefore providing nutrition education and support to prisoners to help them make healthier dietary choices may be more feasible. The third nutrition intervention comprised of nutrition education workshops that allowed prisoners to adopt a more active role by taking part in a project and doing homework. ${ }^{32}$ There was a significant improvement in nutrition practices for prisoners who received this intervention. Improved nutrition practices could benefit prisoners given that they are provided with healthy food options.

The two studies that evaluated mixed interventions had a positive significant effect on at least one measured outcome..$^{34,39}$ However both studies had small sample sizes and were of weak quality, therefore their effectiveness could not be determined. Both studies usefully incorporated behavior change techniques (BCTs) which can encourage positive behavior change. ${ }^{45}$ However neither study mentioned the use of behavior change theory to guide the choice of BCTs used in their interventions, although one study did base its intervention on the self-identified health concerns of its participants. ${ }^{39,46}$

The two smoking cessation studies evaluated the effect of behavioral therapy combined with nicotine replacement on smoking abstinence in prisoners. ${ }^{28,29,33}$ Only one of the interventions had a positive significant effect on smoking abstinence in female prisoners. ${ }^{28,29} \mathrm{~A}$ possible reason for this is that these prisoners received a greater number of support sessions (10 sessions) $)^{28,29}$ compared to those in the other study (2 sessions). ${ }^{33}$ Another possibility is that the intervention involving female prisoners was delivered in a group setting; ${ }^{28,29}$ this strategy is considered to be more 
successful in improving long-term quit rates compared to self-help strategies. ${ }^{47}$ Although both studies did not give details to justify the use of BCTs, both did make reference to previous research based on the use of behavioral therapy to support smoking cessation.

\section{Implications for future research}

The majority of studies included in this review were of weak or moderate quality which brings into question the validity of their findings. They were still included in this review as details of their interventions could be useful in the development of future, more robust studies to improve the cardiovascular health of prisoners. Additionally, most of the studies involved male prisoners only but there is a need for more studies involving female prisoners, particularly as they are a prisoner sub-group that is disproportionately affected with CVD risk factors, especially lack of physical activity. 6,48

Although the two interventions in which prisoners adopted a more active role were of weak quality, ${ }^{32,39}$ there are benefits to incorporating this element in future interventions. By giving prisoners a more active role in interventions, for example, involving them in the intervention design, there can be promotion of selfempowerment, encouragement of communication and shared-decision making and other self-care skills which are traditionally difficult to foster in correctional settings. ${ }^{5}$

Most studies did not describe the process of implementing their interventions, which, given the complexities and influence of the prison environment, is important. Factors such as security and the inflexible nature of the prison regime can create major challenges for prison research. ${ }^{49}$ In our review, details of security levels were given 
in six studies (Tables 2-5). Overall though, there was little detail provided on the difficulties of intervention implementation relating to security. One study was unable to directly assess an outcome because prisoners were not allowed to leave the prison to access the equipment required to carry out this assessment. ${ }^{36}$ Another study attributed a lack of proper 'institutionalization' on its difficulty to fully integrate the intervention into the prison regime, but did not explain what this meant. ${ }^{35}$ Describing the implementation process of these interventions could benefit future researchers who are seeking to improve the cardiovascular health of prisoners.

\section{Conclusion}

In conclusion, this is the first systematic review examining the effectiveness of interventions to improve the key health factors and behaviors of the cardiovascular health of prisoners while incarcerated. Overall, the findings suggest that interventions involving supervised structured physical activity, diet modification, nutrition education and smoking cessation can improve some of these factors such as blood pressure, cholesterol levels and smoking status. However, more rigorous studies are needed to increase the evidence base as there was a lack of high quality studies. The majority of studies used male prisoners and assessed only the shortterm effectiveness of the interventions. Although some studies incorporated behavior change techniques, there was minimal reference made to behavior change theory to justify the use of these techniques within the interventions. There was also little information provided regarding the implementation process of interventions given the challenges of correctional environments. Therefore, future research should include female prisoners, assess short-term and long-term outcomes to evaluate intervention 
effectiveness, and support the use of behavior change techniques with evidencebased theory. Future studies should also provide more detail on the intervention implementation process within the correctional setting, as this information could help other researchers to understand and prepare for the challenges posed by the correctional setting.

\section{References}

1. Mendis S, Armstrong T, Bettcher D, et al. Global status report on noncommnicable diseases 2014. Geneva: World Health Organization; 2014.

2. WHO. Global action plan for the prevention and control of noncommunicable diseases 2013-2020. Geneva: World Health Organization; 2013.

3. Yeates K, Lohfeld L, Sleeth J, Morales F, Rajkotia Y, Ogedegbe O. A global perspective on cardiovascular disease in vulnerable populations. Can J Cardiol. 2015; 31(9): 1081-1093.

4. Fazel S, Baillargeon J. The health of prisoners. Lancet. 2011; 377: 956-965.

5. Plugge E, Martin RE, Hayton P. Noncommunicable diseases and prisoners. In: Enggist S, Møller L, Galea G, Udesen C, eds. Prisons and health. Marmorvej, Copenhagen: WHO Regional Office for Europe; 2014: 81-86.

6. Arries EJ, Maposa S. Cardiovascular risk factors among prisoners: An integrative review. J Forensic Nurs. 2013; 9(1): 52-64.

7. Ritter C, Stover H, Levy M, Etter JF, Elger B. Smoking in prisons: The need for effective and acceptable interventions. J Public Health Pol. 2011; 32(1): 32-45. 
8. Binswanger IA, Krueger PM, Steiner JF. Prevalence of chronic medical conditions among jail and prison inmates in the USA compared with the general population. $J$ Epidemiol Community Health. 2009; 63(11): 912-919.

9. Noonan M, Ginder S. Mortality in local jails and state prisons, 2000-2011, statistical tables. Washington, DC: US Department of Justice, Bureau of Justice Statistics; 2013.

10. Grant JR, Southall PE, Fowler DR, Mealey J, Thomas EJ, Kinlock TW. Death in custody: A historical analysis. J Forensic Sci. 2007; 52(5): 1177-1181.

11. Binswanger IA, Stern MF, Deyo RA, et al. Release from prison-a high risk of death for former inmates. N Engl J Med. 2007; 356(2): 157-165.

12. Enggist S, Møller L, Galea G, Udesen C, eds. Prisons and health. Copenhagen, Denmark: WHO Regional Office for Europe; 2014.

13. NICE. Evidence update 50 - prevention of cardiovascular disease. Manchester: National Institute for Health and Care Excellence. 2014.

14. JBS3. Joint British Societies' consensus recommendations for the prevention of cardiovascular disease (JBS3). Heart. 2014; 100: ii1-ii67.

15. Eckel RH, Jakicic JM, Ard JD, et al. 2013 AHA/ACC guideline on lifestyle management to reduce cardiovascular risk: A report of the American College of Cardiology/American Heart Association Task Force on practice guidelines. J Am Coll Cardiol. 2013.

16. Mendis S, Puska P, Norrving B, eds. Global atlas on cardiovascular disease prevention and control. Geneva: World Health Organization; 2011. 17. Jepson R, Harris F, Platt S, Tannahill C. The effectiveness of interventions to change six health behaviours: A review of reviews. BMC Public Health. 2010; 10(1): 1. 
18. Hillsdon M, Foster C, Cavill NC, H., Naidoo B. The effectiveness of public health interventions for increasing physical activity among adults: A review of reviews:

Evidence briefing summary. 2nd ed. London: Health Development Agency; 2005. 19. Kinner SA, Wang EA. The case for improving the health of ex-prisoners. Am J Public Health. 2014; 104(8): 1352-1355.

20. Restum ZG. Public health implications of substandard correctional health care. Am J Public Health. 2005; 95(10): 1689-1691.

21. Kouyoumdjian FG, Mclsaac KE, Liauw J, et al. A systematic review of randomized controlled trials of interventions to improve the health of persons during imprisonment and in the year after release. Am J Public Health. 2015; 105(4): e13e33.

22. Moher D, Liberati A, Tetzlaff J, Altman DG, The PRISMA Group. Preferred reporting items for systematic reviews and MetaAnalyses: The PRISMA statement. PLoS Med. 2009; 6(7):29. doi:e1000097.

23. Go AS, Mozaffarian D, Roger VL, et al. Heart disease and stroke statistics 2013 update: A report from the American Heart Association. Circulation. 2013;127: e6-e245.

24. Centre for Reviews and Dissemination. Systematic reviews: CRD's guidance for undertaking reviews in health care. York, UK: Centre for Reviews and Dissemination; 2009.

25. EPHPP. Quality assessment tool for quantitative studies. http://www.ephpp.ca/PDF/Quality\%20Assessment\%20Tool_2010_2.pdf. Published 1998. Accessed January 13, 2015. 
26. EPHPP. Quality assessment tool for quantitative studies dictionary.

http://www.ephpp.ca/PDF/QADictionary_dec2009.pdf. Published 1998. Accessed January 13, 2015.

27. Armijo-Olivo S, Stiles CR, Hagen NA, Biondo PD, Cummings GG. Assessment of study quality for systematic reviews: A comparison of the Cochrane Collaboration risk of bias tool and the Effective Public Health Practice Project quality assessment tool: Methodological research. J Eval Clin Pract. 2012; 18(1): 12-18.

28. Cropsey K, Jackson D, Hale G, Carpenter M, Stitzer M. Impact of self-initiated pre-quit smoking reduction on cessation rates: Results of a clinical trial of smoking cessation among female prisoners. Addict Behav. 2011; 36(1-2): 73-78.

29. Cropsey K, Eldridge G, Weaver M, Villalobos G, Stitzer M, Best A. Smoking cessation intervention for female prisoners: Addressing an urgent public health need. Am J Public Health. 2008; 98(10): 1894-1901.

30. Amtmann J, Evans R, Powers J. Measured and perceived effects of a correctional wellness program. Correct Compend. 2001; 26(9): 1-6.

31. Gettman LR, Pollock ML, Durstine JL, Ward A, Ayres J, Linnerud AC. Physiological responses of men to 1, 3, and 5 day per week training programs. Res Q Exercise Sport. 1976; 47(4): 638-646.

32. Curd P, Ohlmann K, Bush H. Effectiveness of a voluntary nutrition education workshop in a state prison. J Correct Health Care. 2013; 19(2): 144-150.

33. Richmond R, Indig D, Butler T, Wilhelm K, Archer V, Wodak A. A randomized controlled trial of a smoking cessation intervention conducted among prisoners. Addiction. 2012; 108(5): 966-974. 
34. Cashin A, Potter E, Stevens W, Davidson K, Muldoon D. Fit for prison: Special population health and fitness programme evaluation. Int J Prison Health. 2008; 4(4): 208-216.

35. Gil-Delgado Y, Domínguez-Zamorano JA, Martínez-Sánchez-Suárez E. Assessment of health benefits from a nutrition program aimed at inmates with cardiovascular risk factors at Huelva prison. Rev Esp Sanid Penit. 2011; 13: 75-83. 36. Pérez-Moreno F, Cámara-Sánchez M, Tremblay JF, Riera-Rubio VJ, Gil-Paisán L, Lucia A. Benefits of exercise training in Spanish prison inmates. Int J Sports Med. 2007; 28(12): 1046-1052.

37. Battaglia C, di Cagno A, Fiorilli G, et al. Benefits of selected physical exercise programs in detention: a randomized controlled study. Int $J$ Environ Res Public Health. 2013; 10(11): 5683-5696.

38. Sioen I, Hacquebard M, Hick G, et al. Effect of ALA-enriched food supply on cardiovascular risk factors in males. Lipids. 2009; 44(7): 603-611.

39. Elwood Martin R, Adamson S, Korchinski M, et al. Incarcerated women develop a nutrition and fitness program: Participatory research. Int J Prison Health. 2013; 9(3): 142-150.

40. Baybutt M, Ritter C, Stöver H. Tobacco use in prison settings: A need for policy implementation. In: Enggist S, Møller L, Galea G, Udesen C, eds. Prisons and health. Marmorvej, Copenhagen: WHO Regional Office for Europe; 2014: 138-147. 41. Djachenko A, St John W, Mitchell C. Smoking cessation in male prisoners: A literature review. Int J Prison Health. 2015; 11(1): 39-48.

42. Herbert K, Plugge E, Foster C, Doll H. Prevalence of risk factors for noncommunicable diseases in prison populations worldwide: A systematic review. Lancet. 2012; 379(9830): 1975-1982. 
43. Tammam J, Gillam L, Gesch B, Stein J. Availability of junk food should be reduced. BMJ. 2012; 345: e7070.

44. Condon L, Hek G, Harris F. Choosing health in prison: Prisoners' views on making healthy choices in English prisons. Health Educ J. 2008; 67(3): 155-166.

45. van Achterberg T, Huisman-de Waal GG, Ketelaar NA, Oostendorp RA, Jacobs JE, Wollersheim HC. How to promote healthy behaviours in patients? an overview of evidence for behaviour change techniques. Health Promot Int. 2011; 26(2): 148-162. 46. Elwood Martin R, Murphy K, Hanson D, et al. The development of participatory health research among incarcerated women in a Canadian prison. Int $J$ Prison Health. 2009; 5(2): 95-107.

47. Zwar NA, Mendelsohn CP, Richmond RL. Supporting smoking cessation. BMJ. 2014; 348: f7535.

48. Plugge EH, Foster CE, Yudkin PL, Douglas N. Cardiovascular disease risk factors and women prisoners in the UK: The impact of imprisonment. Health Promot Int. 2009; 24(4): 334-343.

49. Cislo AM, Trestman R. Challenges and solutions for conducting research in correctional settings: The U.S. experience. Int J Law Psychiatry. 2013; 36(3-4): 304310.

\section{Figure legend}

Figure 1 - Search strategy for the identification of articles 


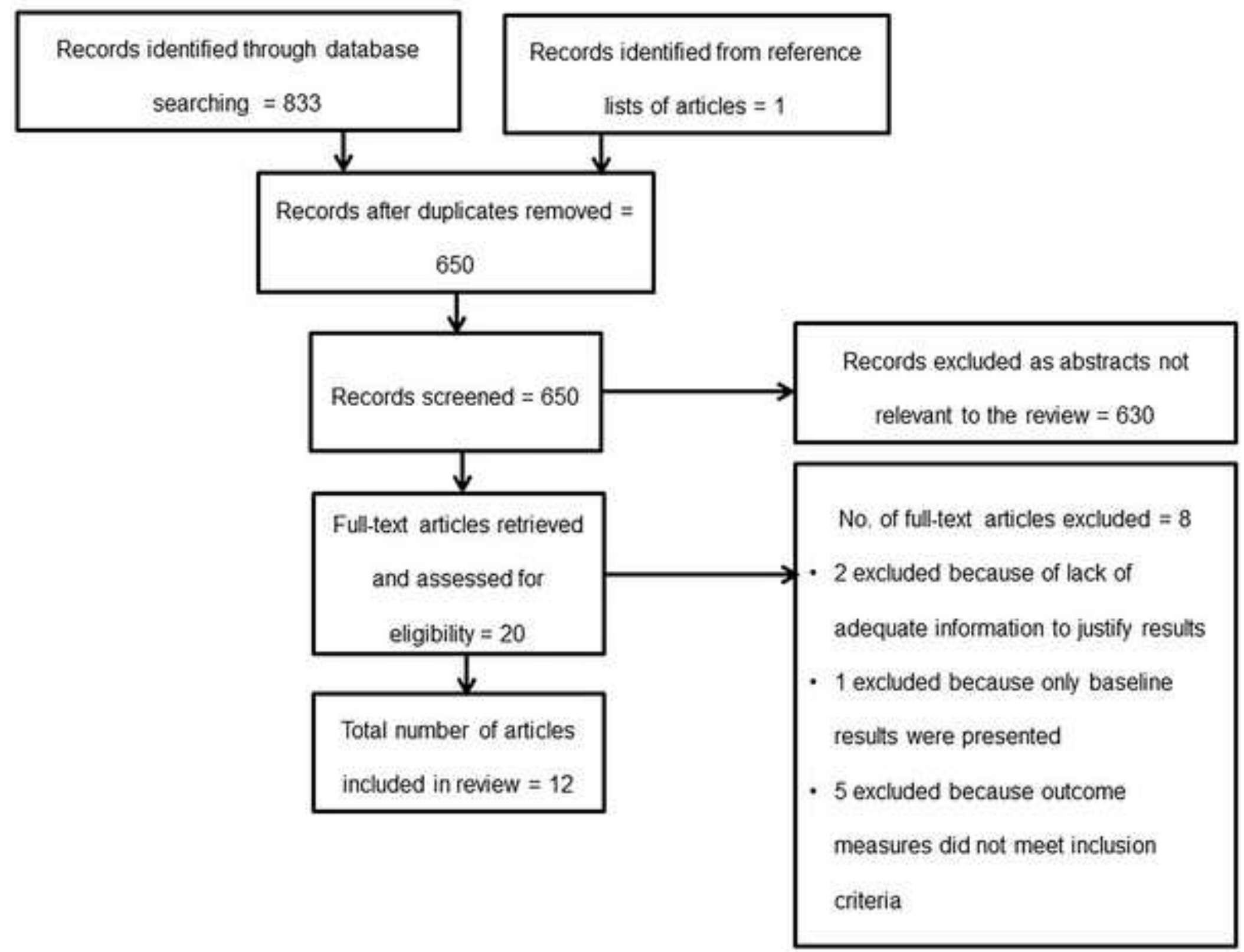




\section{What's new?}

- Prisoners are disproportionately affected by cardiovascular disease and its risk factors but few studies were found to have evaluated the effectiveness of interventions to improve the cardiovascular health of prisoners during incarceration.

- Structured physical activity interventions, nutrition interventions and smoking cessation interventions delivered in a group setting can improve health factors or behaviors of the cardiovascular health of prisoners but more research is needed to assess the effectiveness of mixed interventions.

- More high-quality studies are needed to add to the evidence base and future research should include female prisoners and provide details of the intervention implementation process in the correctional setting. 
Table 1 - Example of search strategy used in CINAHL

\begin{tabular}{|c|c|c|}
\hline $\begin{array}{c}\text { Search } \\
\quad \#\end{array}$ & specific term & no. of results \\
\hline 1 & prisoners & 9734 \\
\hline 2 & offenders & 7872 \\
\hline 3 & 1 OR 2 & 7872 \\
\hline 4 & exercise & 94602 \\
\hline 5 & nutrition & 109021 \\
\hline 6 & diet & 79356 \\
\hline 7 & 5 OR 6 & 79356 \\
\hline 8 & smoking cessation & 16707 \\
\hline 9 & training & 11192 \\
\hline 10 & 4 OR 9 & 11192 \\
\hline 11 & wellness & 14866 \\
\hline 12 & health promotion & 70462 \\
\hline 13 & cardiovascular & 450713 \\
\hline 14 & 7 OR 8 OR 10 OR 11 OR 12 OR 13 & 450713 \\
\hline 15 & 3 AND 14 & 33 \\
\hline
\end{tabular}


Table 2 - Summary of the studies using interventions based on structured physical activity only

\begin{tabular}{|c|c|c|c|c|}
\hline $\begin{array}{l}\text { Study; } \\
\text { country }\end{array}$ & $\begin{array}{l}\text { Study design; } \\
\text { setting }\end{array}$ & $\begin{array}{l}\text { Sample size }(\mathrm{n}) \text { and } \\
\text { characteristics }\end{array}$ & Intervention & Outcome \\
\hline $\begin{array}{l}\text { Battaglia } \\
\text { et al, } \\
2013^{37} \text {; } \\
\text { Italy }\end{array}$ & $\begin{array}{l}\text { RCT; maximum } \\
\text { security prison }\end{array}$ & $\begin{array}{l}\mathrm{n}=75 \\
\text { Male prisoners, } \leq 50 \text { years, } \\
\text { no medical conditions that } \\
\text { would prevent participation } \\
\text { in exercise. }\end{array}$ & $\begin{array}{l}\text { Two intervention groups: } 1 \text { ) cardiovascular plus } \\
\text { resistance training or CRT ( } n=25) \text { : aerobic exercises } \\
\text { alternating with resistance strength exercises; } 2 \text { ) high } \\
\text { intensity strength training or HIST ( } n=25) \text { : anaerobic } \\
\text { exercises alternating with maximal strength exercises } \\
\text { and active recovery. } \\
\text { Duration and intensity of sessions for both groups } \\
\text { were gradually increased. Sessions were } 1 \text { hour long, } \\
\text { twice per week. } \\
\text { Control group ( } n=25 \text { ) received no intervention and } \\
\text { performed their habitual activities. Duration was } 9 \\
\text { months. }\end{array}$ & $\begin{array}{l}\text { CRT group: Significant differences between this } \\
\text { group and the control group for oxygen saturation, } \\
\text { HDL and all fitness variables except abdominal } \\
\text { strength and endurance. No significant differences } \\
\text { between this group and the control group for all } \\
\text { other health status variables. Significant differences } \\
\text { between this group and the HIST group for } \\
\text { abdominal and upper body muscular strength and } \\
\text { endurance. } \\
\text { HIST group: Significant differences between this } \\
\text { group and the control group for oxygen saturation, } \\
\text { upper body muscular strength and endurance. No } \\
\text { significant differences between this group and the } \\
\text { control group observed for all other health status } \\
\text { and fitness level variables. }\end{array}$ \\
\hline $\begin{array}{l}\text { Pérez- } \\
\text { Moreno et }\end{array}$ & $\begin{array}{l}\text { RCT; minimum } \\
\text { security prison }\end{array}$ & $\begin{array}{l}\mathrm{n}=31 \\
\text { Male prisoners, } 30-55\end{array}$ & $\begin{array}{l}\text { Cardiorespiratory and resistance training intervention } \\
(n=14) . \text { Sessions were } 90 \text { minutes long, } 3 \text { days per }\end{array}$ & $\begin{array}{l}\text { No significant differences between the intervention } \\
\text { and control groups. }\end{array}$ \\
\hline
\end{tabular}







3-day group: Significant differences between this group and the control group for waist girth and all physical fitness variables except maximum HR and resting blood pressure. Significant differences between this group and the 1-day group for resting $H R$, maximum $H R$ and $V_{2}$ max.

1-day group: Significant differences between this group and the control group for all physical fitness variables except maximum HR and resting blood pressure. No significant differences observed for body composition variables.

BP - blood pressure; HDL - high-density lipoprotein; LDL - low-density lipoprotein; HR - heart rate; TSF - total skinfold fat; $V_{2}$ max - maximum pulmonary ventilation 
Table 3 - Summary of the studies using nutrition interventions




special diets.

\begin{tabular}{|c|c|c|c|c|}
\hline Sioen et & Cohort study; & $\mathrm{n}=70$ & Participants given a standard diet for 6 weeks, and & Significant differences compared to baseline for DBP \\
\hline al, 200938; & high security & Healthy male prisoners, 22- & then supplied with an n-3 PUFA (polyunsaturated & and HDL in smokers. No significant differences \\
\hline \multirow[t]{3}{*}{ Belgium } & prison & 65 years. & fatty acids) enriched diet for 12 weeks. The new & compared to baseline for all other anthropometric and \\
\hline & & & diet contained $6.5 \mathrm{~g}$ of $\mathrm{n}-3$ PUFA/day compared to & clinical variables. \\
\hline & & & $4 \mathrm{~g}$ of $\mathrm{n}-3$ PUFA/day in the standard diet. & \\
\hline
\end{tabular}

IDF - International Diabetes Federation; DBP - diastolic blood pressure; HDL - high-density lipoprotein 
Table 4 - Summary of the studies using interventions based on physical activity and education sessions

\begin{tabular}{|c|c|c|c|c|}
\hline $\begin{array}{l}\text { Study; } \\
\text { country }\end{array}$ & $\begin{array}{c}\text { Study design; } \\
\text { setting }\end{array}$ & $\begin{array}{l}\text { Sample size (n) and } \\
\text { characteristics }\end{array}$ & Intervention & Outcome \\
\hline $\begin{array}{l}\text { Elwood } \\
\text { Martin et } \\
\text { al, 2013³; } \\
\text { Canada }\end{array}$ & $\begin{array}{c}\text { Before and } \\
\text { after study; } \\
\text { medium } \\
\text { security prison }\end{array}$ & $\begin{array}{l}\mathrm{n}=28 \\
\text { Female prisoners } \geq 18 \text { years. }\end{array}$ & $\begin{array}{l}\text { Intervention was partly designed by prisoners } \\
\text { through a participatory research process and } \\
\text { les by a prisoner certified in health and fitness. } \\
\text { Participants received a food guide and } \\
\text { personalized food chart which were used to } \\
\text { help self-monitor eating behavior, and } \\
\text { attended a nutrition education session once } \\
\text { per week. Participants joined a group circuit } \\
\text { class or followed personalized exercise plans. } \\
\text { Duration was } 6 \text { weeks. }\end{array}$ & $\begin{array}{l}\text { Significant improvement in chest measurement compared } \\
\text { to baseline. No significant changes observed for weight, } \\
\text { BMI and waist-to-hip ratio. }\end{array}$ \\
\hline $\begin{array}{l}\text { Cashin et } \\
\text { al, } 2008^{34} \text {; } \\
\text { Australia }\end{array}$ & $\begin{array}{c}\text { RCT; } \\
\text { maximum } \\
\text { security prison }\end{array}$ & $\begin{array}{l}n=20 \\
\text { Male prisoners } \geq 40 \text { years } \\
\text { who either had chronic } \\
\text { illness or } \geq 2 \text { risk factors for } \\
\text { chronic illness. }\end{array}$ & $\begin{array}{l}\text { Participants attended sessions on cardio- } \\
\text { respiratory endurance, strength and flexibility } \\
\text { training. Sessions were led by prisoner peer } \\
\text { leaders. Exercise was group-based but each } \\
\text { participant had a personal plan. Participants } \\
\text { attended } 3 \text { health education classes on healthy } \\
\text { eating and self-management in the prison }\end{array}$ & $\begin{array}{l}\text { Significant differences between intervention and control } \\
\text { groups for resting HR and endurance. A significant } \\
\text { difference was observed between the two groups for DBP, } \\
\text { with the control group seeing the greatest improvement } \\
\text { after the intervention (this difference occurred on pre- } \\
\text { testing). No significant differences observed for all other } \\
\text { measured outcomes. }\end{array}$ \\
\hline
\end{tabular}


Control group continued with their usual

exercise regime $(n=20)$. Duration was 12

weeks.

DBP - diastolic blood pressure; HR - heart rate 
Table 5 - Summary of the studies using interventions based on smoking cessation only

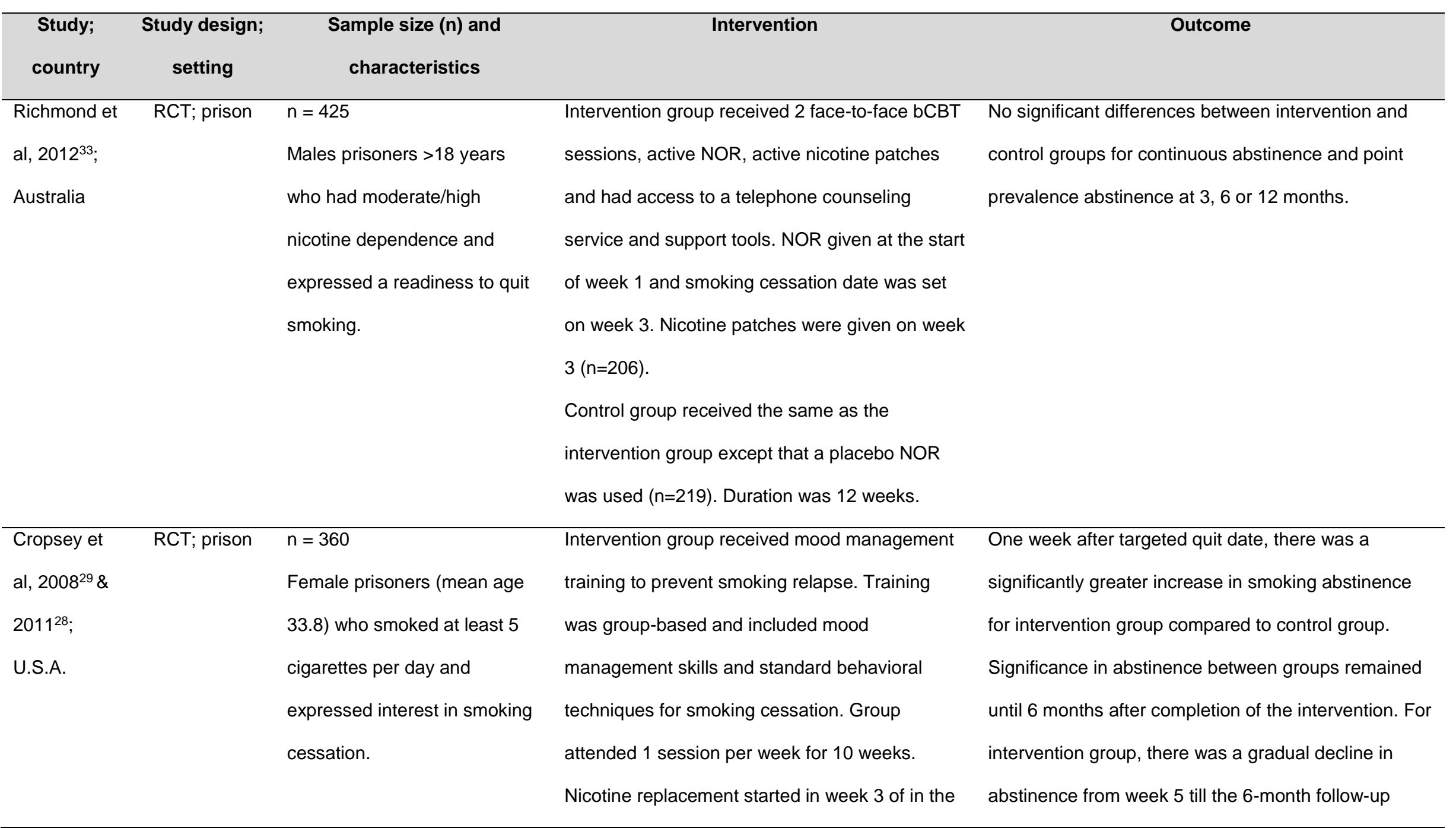


intervention and participants were asked to

make quit attempts during weeks 3 and 4

point. $46 \%$ of intervention participants relapsed after 1

$(n=250)$

Control group were on a 6-month waiting list

$(n=289)$. Duration was 10 weeks.

bCBT - brief cognitive-behavioral therapy; NOR - nortriptyline 
Table 6 - Ratings of items of methodological quality based on criteria by the EPHPP

$\begin{array}{ccccccc}\text { Selection } & \text { Study } & \text { Confoun- } & \text { Blinding } & \text { Data } & \text { Withdrawals } & \text { Global } \\ \text { bias } & \text { design } & \text { ders } & & \text { collection } & \text { and } & \text { rating } \\ & & & & & \text { methods } & \text { dropouts }\end{array}$

Battaglia

et al, Moderate Strong Strong Weak Strong Moderate Moderate $2013^{37}$

Elwood

Moderate Weak

Weak

Weak

Weak

Weak

al, $2013^{39}$

Curd et al, $2013^{32}$

Weak Moderate Stron

Weak Weak

Strong

Weak

Richmond

et al,

Moderate Strong

Weak

Moderate Strong

Strong

Moderate

$2012^{33}$

Gil-

Delgado

et al,

Moderate Moderate Strong

Moderate Strong

Moderate

Strong

$2011^{35}$

Sioen et

al, $2009^{38}$

Moderate Moderate Strong Moderate Strong

Strong

Strong

Cropsey

et al,

$2008^{29} \&$ Strong Strong Strong Moderate Strong Weak Moderate

$2011^{28}$

Cashin et

al, $2008^{34}$

Strong Weak

Moderate Strong

Moderate

Weak

Perez-

Moreno et 
al, $2007^{36}$

1

2

3

4

5

7

8

9

10

11

12

13

14

15

16

17

18

19

20

21

22

23

24

25

26

27

28

29

30

31

32

33

34

35

36

37

38

39

40

41

42

43

44

45

46

47

48

49

50

51

52

53

54

55

56

57

58

59

60

61

62

63

64

65 